Sharif University of Technology
Scientia Iranica
Transactions E: Industrial Engineering
wCIENTIA

Research Note

\title{
A two-warehouse inventory model with preservation technology investment and partial backlogging
}

\author{
S.R. Singh ${ }^{\mathrm{a}}$ and H. Rathore ${ }^{\mathrm{b}, *}$ \\ a. Department of Mathematics, D. N. College, Meerut, U. P., India. \\ b. Research Scholar, Banasthali University, Banasthali, Rajasthan, India. \\ Received 20 September 2014; received in revised form 7 February 2015; accepted 6 September 2015
}

\author{
KEYWORDS \\ Two-warehouse; \\ Preservation \\ technology; \\ Stock-dependent \\ demand; \\ Partial backlogging; \\ Inflation.
}

\begin{abstract}
In today's global world, preservation technology becomes very important due to rapid changes in environment. To study this concept, in this article, we have developed the two-warehouse inventory model with the consideration of preservation technology investment. Demand rate is treated as linear function of instantaneous stock level. The limited storage area $(\mathrm{OW})$ is used for the storage of the stock. The extra amount of stock beyond the capacity of the Owned Warehouse (OW) is stored in the Rented Warehouse (RW). The holding cost of rented warehouse is greater than the holding cost of Owned Warehouse (OW); thus, the stock of Rented Warehouse (RW) is used first and then, the stock of Owned Warehouse (OW) is consumed. The shortages are allowed and partially backlogged under the effect of inflation. The main aim of this study is to find the optimal value of the total cost function. Numerical illustrations and sensitivity analysis are given at the end of this article.
\end{abstract}

(C) 2016 Sharif University of Technology. All rights reserved.

\section{Introduction}

Every organization stores items to maintain the longterm relationship with its customers. It is a very common phenomenon that the amount of stock exceeds the capacity of the storage space of the owned warehouse, which is limited to a certain level. In such situation, the organization hires a rented warehouse at a high holding cost. In literature, the concept of twowarehouse has first been introduced by Hartley [1]. Sarma [2] is the first who has used the concept of limited storage capacity of owned warehouse in inventory control modeling. After that, many authors have studied the two-warehouse inventory problem. Kumari et al. [3], Agrawal and Banerjee [4], Kumar et al. [5], Singh et al. [6], Singh and Rathore [7], and Singh and

*. Corresponding author.

E-mail addresses: ashivrajpudir@gmail.com (S.R. Singh); brathorehimanshu2003@gmail.com (H. Rathore)
Rathore [8] have studied the two-warehouse problem with partially backlogged shortages. Sarkar et al. [9], Sarkar and Moon [10], Khanra et al. [11], and Sarkar et al. [12] have studied the inventory control model with partially backlogged shortages.

Zhou and Yang [13] have studied the twoinventory problem with stock-dependent demand rate. Further, the stock-dependent demand rate with the concept of two-warehouse has been studied by Yadav et al. [14], Singh et al. [15], Gayen and Pal [16] etc. Dye and Ouyang [17], Ghiami et al. [18], and Sarkar and Sarkar [19] concentrated on the concept of stock-dependent demand with partially backlogged shortages.

Due to rapid changes in environment, preservation technology becomes very important as well as essential to preserve the items. In the abovementioned papers, like Sarkar et al. [20] and Sarkar and Sarkar [21], the deterioration rate is treated as an uncontrollable variable. Through some procedural 
changes and preservation techniques, the deterioration rate can be controlled to a certain level. Recently, this concept has been a main point of concentration in the field of inventory control modeling. In literature, Hsu et al. [22] developed a deteriorating inventory model in which they considered that the retailer could invest in preservation technology to reduce deterioration. For further review, we can go through the work of Lee and Dye [23], Hsieh and Dye [24], Dye [25], Xue et al. [26], Zhang et al. [27], Tayal et al. [28], Zhang et al. [29], etc.

The concept of inflation has first been studied by Buzacott [30]. After that, many authors have extended the work of Buzacott. Wee et al. [31] and Yang [32] focused on two-warehouse problem with partially backlogged shortages under the effect of inflation. Singh and Rathore [33-35] have studied the effect of preservation technology in an inflationary environment. Many other authors have considered the effect of inflation in their inventory control modeling, like Singh et al. [36], Singh et al. [37], Patra and Ratha [38], Sarkar et al. [3940], Sarkar et al. [41], Singh and Rathore [42-43], etc.

In the present article, we have developed a twowarehouse inventory model with controllable deterioration rate. The demand rate is a linear function of instantaneous stock level. The shortages are permitted and partially backlogged. For the storage of items, twowarehouse system is considered with limited storage capacity at Owned Warehouse (OW) and unlimited storage capacity at Rented Warehouse (RW). In the second section, assumptions and notations are given for mathematical model formulation. Solution of the mathematical model is described in the third section. At the end of this paper, numerical illustration and sensitivity analysis are provided. The convexity of the model is shown in Figures 1 and 2 .

\section{Assumptions and notations}

The assumptions and notations which are used in the mathematical model formulation are as follows:

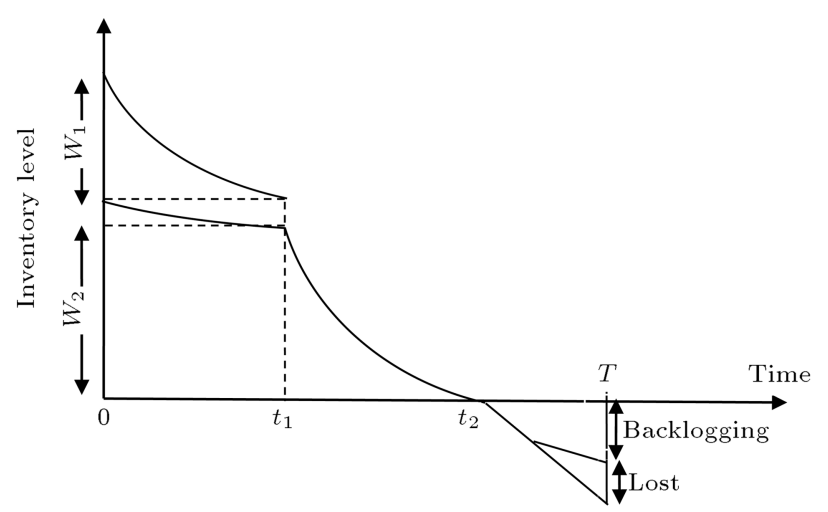

Figure 1. Inventory functioning in two-warehouse system.

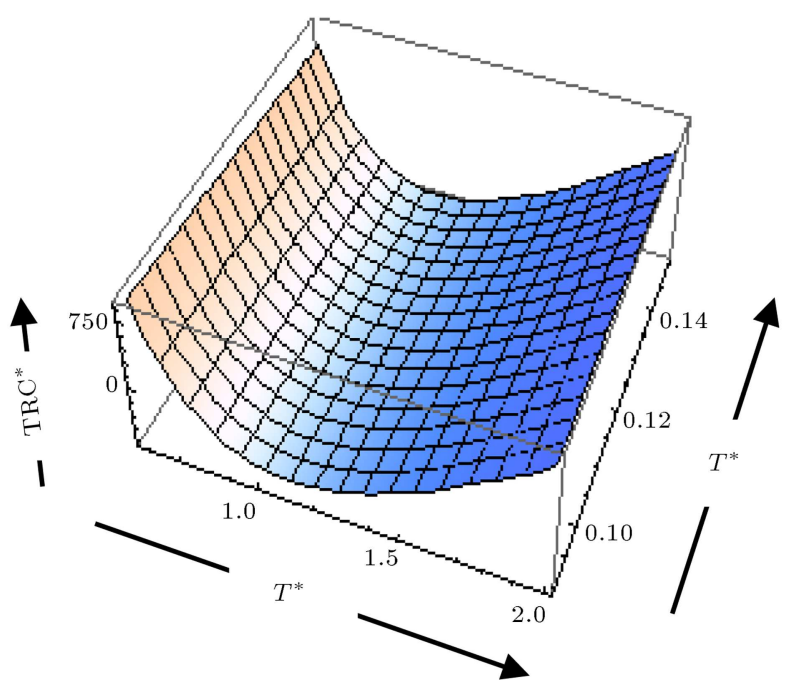

Figure 2. Convexity of $\mathrm{TRC}^{*}$ with respect to $T^{*}$ and $t_{1}^{*}$.

\subsection{Notation}

- $D(I(t))$ : Instantaneous stock-level-dependent demand rate;

- $Q$ : The order quantity;

- $\theta$ : Constant deterioration rate;

- $m(\xi):\left(=\theta\left(1-e^{-a \xi}\right)\right)$ reduced deterioration rate, a $\xi>0$

- $\xi$ : The Preservation Technology (PT) cost, $\xi>0$;

- $\tau_{\theta}$ : Resultant deterioration rate, $\tau_{\theta}=(\theta-m(\xi))$;

- $r$ : Difference of inflation and time discounting;

- A: Ordering cost;

- $h_{1}$ : The holding cost (per unit per time unit) of Rented Warehouse (RW);

- $h_{2}$ : The holding cost (per unit per time unit) of Owned Warehouse (OW);

- $C$ : The unit purchasing cost;

- $C_{s}$ : The shortage cost;

- $C_{L}$ : The lost sale cost;

- $W_{2}$ : The limited space area of OW;

- $W_{1}$ : Maximum inventory level in RW;

- B: Maximum backorder level;

- $t_{1}$ : The time period at which inventory level in RW reaches zero;

- $t_{2}$ : The time period at which inventory level in $\mathrm{OW}$ reaches zero;

- $T$ : The cycle length;

- $I_{1}(t)$ : The inventory level in RW during time period $\left[0, t_{1}\right]$

- $I_{2}(t)$ : The inventory level in OW during time period $\left[0, t_{1}\right]$ 
- $I_{3}(t)$ : The inventory level in OW during time period $\left[t_{1}, t_{2}\right]$;

- $I_{4}(t)$ : The inventory level in OW during time period $\left[t_{2}, T\right]$

- TRC: The present worth of the total relevant cost;

- PC: The purchase cost;

- HC: The present worth of holding cost;

- SC: The present worth of shortage cost;

- LC: The present worth of lost sale cost.

\subsection{Assumptions}

- Demand rate is stock-dependent and taken as the following form:

$$
D(I(t))=\left\{\begin{array}{l}
\alpha+\beta I(t) ; I(t)>0 ; \\
\alpha ; I(t) \leq 0 ;
\end{array}\right.
$$

- Shortages are allowed and partially backlogged where backlogging rate is:

$$
B(t)=\frac{1}{(1+t \delta)}
$$

where $t$ is the waiting time and $0<\delta<1$ is the backlogging parameter;

- Time horizon is infinite;

- Preservation technology is used to reduce the deterioration rate;

- Replenishment rate is infinite and lead time is zero;

- The Owned Warehouse (OW) has the limited space of $W_{2}$ units, whereas the rented warehouse has unlimited space area;

- The holding cost $\left(h_{1}\right)$ of RW is greater than the holding cost $\left(h_{2}\right)$ of OW; therefore, consumption of inventory starts only when inventory level of RW reaches zero;

- The charges for transportation as well as time between RW and OW are negligible.

\section{Mathematical model formulation}

After satisfying the backlogged shortages of the previous period, the inventory level at time $t=0$ is $S$, out of which $W$ units are stored in OW and the remaining SW units are stored in RW.

Inventory level of RW decreases due to demand and deterioration during the time interval $\left[0, t_{1}\right]$ and at $t=t_{1}$, it reaches the zero level. After time $t_{1}$, demand of items is fulfilled by using inventory of OW during time interval $\left[t_{1}, t_{2}\right]$. In the time period $\left[t_{2}, T\right]$, shortages occur and are partially backlogged. The description model is presented in Figure 3.

The inventory depletion in RW is represented by

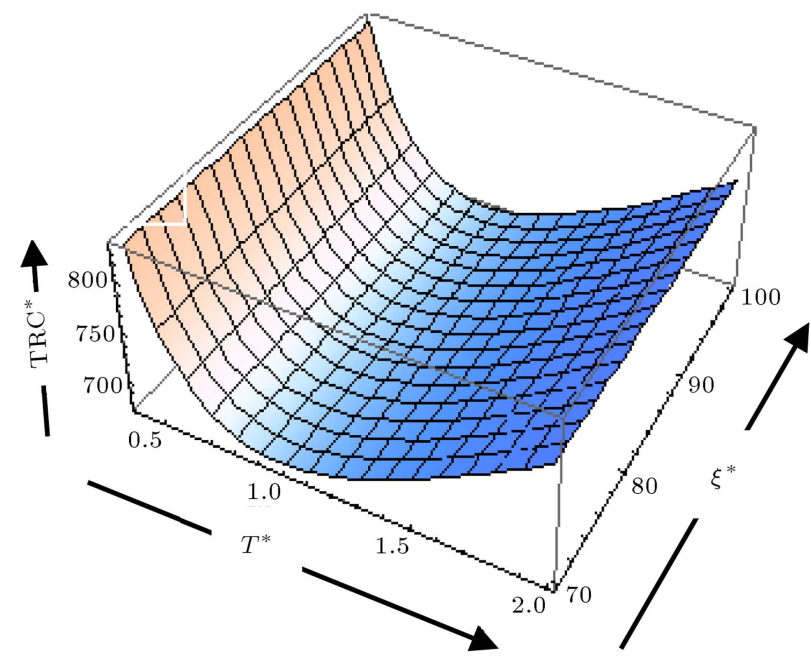

Figure 3. Convexity of $\mathrm{TRC}^{*}$ with respect to $T^{*}$ and $\xi^{*}$.

differential equation, given as follows:

$$
\frac{d\left(I_{1}(t)\right)}{d t}+\tau_{\theta} I_{1}(t)=-\left(\alpha+\beta I_{1}(t)\right) ; \quad 0 \leq t \leq t_{1} .
$$

And in OW, functioning of inventory is as follows:

$$
\begin{aligned}
& \frac{d\left(I_{2}(t)\right)}{d t}+\tau_{\theta} I_{2}(t)=0 ; \quad 0 \leq t \leq t_{1}, \\
& \frac{d\left(I_{3}(t)\right)}{d t}+\tau_{\theta} I_{3}(t)=-\left(\alpha+\beta I_{3}(t)\right) ; \quad t_{1} \leq t \leq t_{2}, \\
& \frac{d\left(I_{4}(t)\right)}{d t}=-\left(\frac{\alpha}{(1+\delta(T-t))}\right) ; \quad t_{2} \leq t \leq T .
\end{aligned}
$$

Under the boundary conditions, $I_{1}(t=0)=W_{1}, I_{1}(t=$ $\left.t_{1}\right)=0, I_{2}(t=0)=W_{2}, I_{2}\left(t=t_{1}\right)=I_{3}\left(t=t_{1}\right)$, $I_{3}\left(t=t_{d}\right)=I_{4}\left(t=t_{d}\right), I_{4}\left(t=t_{2}\right)=0, I_{5}\left(t=t_{2}\right)=0$. Now, by solving the above equations, we obtain:

$$
\begin{aligned}
& I_{1}(t)=\frac{\alpha}{\left(\beta+\tau_{\theta}\right)}\left(e^{\left(\beta+\tau_{\theta}\right)\left(t_{1}-t\right)}-1\right), \\
& I_{2}(t)=e^{-t \tau_{\theta}} W_{2}, \\
& I_{3}(t)=\frac{\alpha}{\left(\beta+\tau_{\theta}\right)}\left(e^{\left(\beta+\tau_{\theta}\right)\left(t_{2}-t\right)}-1\right), \\
& I_{4}(t)=-\alpha\left[\left(t-t_{2}\right)\right], \\
& W_{1}=\frac{\alpha}{\left(\beta+\tau_{\theta}\right)}\left(e^{\left(\beta+\tau_{\theta}\right) t_{1}}-1\right) .
\end{aligned}
$$

From $I_{2}\left(t=t_{1}\right)=I_{3}\left(t=t_{1}\right)$ :

$$
t_{2}=t_{1}+\frac{1}{\left(\tau_{\theta}+\beta\right)} \log \left(W_{2} e^{t_{1} \tau_{\theta}}+\frac{\alpha}{\left(\tau_{\theta}+\beta\right)}\right) .
$$

Maximum backlogged amount IB $=-I_{4}(t=T)$ :

$\mathrm{IB}=\alpha\left[\left(T-t_{2}\right)\right]$.

Order quantity $Q=B+W_{1}+W_{2}$ : 


$$
Q=\frac{\alpha}{\left(\beta+\tau_{\theta}\right)}\left(e^{\left(\beta+\tau_{\theta}\right) t_{1}}-1\right)+W_{2}+\alpha\left(T-t_{2}\right)
$$

The total relevant cost includes the following cost parameters:

1. The ordering cost $=\mathrm{A}$.

2. The purchase cost $=\mathrm{CQ}$.

3. The present worth of Holding Cost $(\mathrm{HC})$ is:

$$
\begin{aligned}
\mathrm{HC}= & h_{1}\left[\int_{0}^{t_{1}} I_{1}(t) e^{-r t} d t\right]+h_{2}\left[\int_{0}^{t_{1}} I_{2}(t) e^{-r t} d t\right. \\
& \left.+\int_{t_{1}}^{t_{2}} I_{3}(t) e^{-r t} d t\right], \\
\mathrm{HC}= & h_{1}\left[\frac { \alpha } { \beta + \tau _ { \theta } } \left(e^{\left(\beta+\tau_{\theta}\right) t_{1}}\left(\frac{1-e^{-\left(\beta+\tau_{\theta}+r\right) t_{1}}}{\left(\beta+\tau_{\theta}+r\right)}\right)\right.\right. \\
& \left.\left.+\left(\frac{e^{-r t_{1}}-1}{r}\right)\right)\right] \\
& +h_{2}\left[W_{2}\left(\frac{1-e^{-\left(r+\tau_{\theta}\right)^{t_{1}}}}{\left(r+\tau_{\theta}\right)}\right)\right. \\
& \left.+\frac{\alpha}{\left(\beta+\tau_{\theta}\right)}\left(\frac{e^{-r t_{2}}-e^{-r t_{1}}}{r}\right)\right] \\
& h_{2}\left[\frac{\alpha}{\left(\beta+\tau_{\theta}\right)}\left(e^{\left(\beta+\tau_{\theta}\right) t_{2}}\right)\right] . \\
& \left.\left(\frac{e^{-\left(\beta+\tau_{\theta}+r\right) t_{1}}-e^{-\left(\beta+\tau_{\theta}+r\right)} t_{2}}{\left(\beta+\tau_{\theta}+r\right)}\right)\right)
\end{aligned}
$$

4. The present worth of Shortage Cost (SC) is:

$$
\begin{aligned}
\mathrm{SC}= & C_{s}\left(-\int_{t_{1}}^{T} I_{4}(t) e^{-r t} d t\right), \\
\mathrm{SC}= & \alpha C_{s}\left(t_{2}\left(r \frac{T^{2}-t_{2}^{2}}{2}-\left(T-t_{2}\right)\right)\right. \\
& \left.+\left(\frac{T^{2}-t_{2}^{2}}{2}-r \frac{T^{3}-t_{2}^{3}}{2}\right)\right) .
\end{aligned}
$$

5. The present worth of Lost sale Cost (LC) is:

$$
\begin{aligned}
\mathrm{LC}= & C_{L}\left(\alpha \int_{t_{2}}^{T}\left(1-\frac{1}{(1+\delta(T-t))}\right) e^{-r t} d t\right), \\
\mathrm{LC}= & \alpha C_{L}\left(\left(T-t_{2}\right)-r \frac{T^{2}-t_{2}^{2}}{2}-\frac{1}{\delta}\right. \\
& \left.\log \left(1+\delta\left(T-t_{2}\right)\right)\right)
\end{aligned}
$$

$$
\begin{aligned}
& +\alpha C_{L}\left(\frac { r } { \delta } \left(-(\delta T+1) \log \left(1+\delta\left(T-t_{2}\right)\right)\right.\right. \\
& \left.\left.-\left(T-t_{2}\right)\right)\right) .
\end{aligned}
$$

Therefore, the total relevant cost is as follows:

$$
\operatorname{TRC}\left(t_{1}, \xi, T\right)=(1 / T)[A+P C+H C+S C+L C] .
$$

To minimize total relevant cost, we differentiate total relevant cost, $K=T C\left(t_{1}, \xi, T\right)$ with respect to to $t_{1}, \xi$ and $T$, for optimal value necessary conditions are:

$$
\begin{aligned}
& \frac{\partial T C\left(t_{1}, \xi, T\right)}{\partial t_{1}}=0, \quad \frac{\partial T C\left(t_{1}, \xi, T\right)}{\partial \xi}=0, \\
& \frac{\partial T C\left(t_{1}, \xi, T\right)}{\partial T}=0,
\end{aligned}
$$

provided the determinant of principal minor of hessian matrix are positive definite, i.e. $\operatorname{det}(\mathrm{H} 1)>0$, $\operatorname{det}(\mathrm{H} 2)>0, \operatorname{det}(\mathrm{H} 3)>0$ where $\mathrm{H} 1, \mathrm{H} 2, \mathrm{H} 3$ is the principal minor of the Hessian-matrix.

Hessian matrix of the total cost function is as follows:

$$
\left[\begin{array}{ccc}
\frac{\partial^{2} T C}{\partial t_{1}^{2}} & \frac{\partial^{2} T C}{\partial t_{1} \partial \xi} & \frac{\partial^{2} T C}{\partial t_{1} \partial T} \\
\frac{\partial^{2} T C}{\partial \xi \partial t_{1}} & \frac{\partial^{2} T C}{\partial \xi^{2}} & \frac{\partial^{2} T C}{\partial \xi \partial T} \\
\frac{\partial^{2} T C}{\partial T \partial t_{1}} & \frac{\partial^{2} T C}{\partial T \partial \xi} & \frac{\partial^{2} T C}{\partial T^{2}}
\end{array}\right]
$$

\section{Numerical illustration}

For illustration of the proposed model, we consider the following inventory system in which values of different parameters in proper units are:

$$
\begin{aligned}
& A=500 ; \alpha=270 ; \beta=30 ; C=2 ; C_{s}=1.6 \\
& C_{L}=1.5 ; \theta=0.05 ; \delta=0.1 ; r=0.02 \\
& h_{1}=0.3 ; h_{2}=0.2 ; W=50 ; a=3 .
\end{aligned}
$$

Using mathematical software Mathematica 6, we get the optimal values of $t_{1}^{*}=0.11729, t_{2}^{*}=1.07937$, $T^{*}=1.34624, \xi^{*}=88.1963, Q^{*}=252.544$, and $\mathrm{TRC}^{*}=691.346$.

\section{Sensitivity analysis}

To test the sensitivity of this model, we performed a sensitivity analysis by varying values of some important parameters like demand parameters ' $\alpha$ ' and ' $\beta$ ', deterioration rate $\theta$, etc. The effect of change in parameters is shown in Table 1 . Keen observation of all the three tables above reveals the following facts: 
Table 1. Sensitivity analysis of optimal values different parameters with respect to other parameters.

\begin{tabular}{|c|c|c|c|c|c|c|}
\hline & $t_{1}^{*}$ & $t_{2}^{*}$ & $T^{*}$ & $\xi^{*}$ & $Q^{*}$ & TRC $^{*}$ \\
\hline \multicolumn{7}{|c|}{ Change in $\alpha$} \\
\hline 265 & 0.11779 & 1.07436 & 1.84416 & 87.4587 & 254.35 & 688.325 \\
\hline 275 & 0.116804 & 1.0844 & 1.81278 & 88.9354 & 250.649 & 694.168 \\
\hline 285 & 0.115871 & 1.09449 & 1.78314 & 90.4211 & 255.057 & 704.129 \\
\hline \multicolumn{7}{|c|}{ Change in $\beta$} \\
\hline 25 & 0.127449 & 1.55469 & 1.82933 & 83.8983 & 124.483 & 531.698 \\
\hline 35 & 0.108774 & 0.753198 & 1.82753 & 94.6152 & 340.425 & 777.641 \\
\hline 45 & 0.0965022 & 0.336423 & 1.82665 & 108.938 & 452.725 & 860.515 \\
\hline \multicolumn{7}{|c|}{ Change in $\theta$} \\
\hline 0.04 & 0.11729 & 1.07818 & 1.82824 & 73.5525 & 252.865 & 690.997 \\
\hline 0.055 & 0.11729 & 1.07997 & 1.82824 & 80.2088 & 252.382 & 691.17 \\
\hline 0.06 & 0.11729 & 1.08056 & 1.82824 & 110.162 & 252.222 & 691.695 \\
\hline \multicolumn{7}{|c|}{ Change in $\delta$} \\
\hline 0.15 & 0.112751 & 1.07491 & 1.80149 & 90.0809 & 246.5 & 678.325 \\
\hline 0.17 & 0.111669 & 1.07384 & 1.79537 & 90.5794 & 245.13 & 675.398 \\
\hline 0.2 & 0.110454 & 1.07265 & 1.78844 & 91.1642 & 243.574 & 672.164 \\
\hline \multicolumn{7}{|c|}{ Change in $r$} \\
\hline 0.015 & 0.11382 & 1.07596 & 1.78898 & 89.5996 & 242.844 & 679.354 \\
\hline 0.025 & 0.120645 & 1.08266 & 1.8723 & 87.0001 & 263.571 & 704.562 \\
\hline 0.03 & 0.123892 & 1.08584 & 1.92161 & 85.9734 & 276.045 & 719.121 \\
\hline \multicolumn{7}{|c|}{ Change in $W$} \\
\hline 40 & 0.115078 & 0.74409 & 1.79946 & 98.4872 & 325.267 & 765.808 \\
\hline 60 & 0.119408 & 1.41462 & 1.85669 & 81.4136 & 179.733 & 599.777 \\
\hline 80 & 0.123845 & 1.51462 & 1.91253 & 72.3996 & 149.733 & 367.155 \\
\hline
\end{tabular}

1. Increase in $\alpha$ results in decrement in $t_{1}^{*}$ and $T^{*}$, but increment in $t_{2}^{*}, \mathrm{TRC}^{*}, Q^{*}$, and $\xi^{*}$;

2. Increase in $\beta$ results in decrement in $t_{1}^{*}, t_{2}^{*}$, and $T^{*}$, but increment in $\mathrm{TRC}^{*}, Q^{*}$, and $\xi^{*}$;

3. Increase in $\theta$ results in decrement in $Q^{*}$, but increment in $t_{2}^{*}, \mathrm{TRC}^{*}$, and $\xi^{*}$;

4. Increase in $r$ results in decrement in $T^{*}$ and $\mathrm{TRC}^{*}$, but increment in $t_{1}^{*}, t_{2}^{*}, \xi^{*}$, and $Q^{*}$;

5. Increase in $W$ results in decrement in $\xi^{*}, Q^{*}$, and $\mathrm{TRC}^{*}$, but increment in $t_{1}^{*}, t_{2}^{*}$, and $T^{*}$;

6. Increase in $\delta$ results in increment in $\xi^{*}$, but decrement in $t_{1}^{*}, t_{2}^{*}, T^{*}, \mathrm{TRC}^{*}$, and $Q^{*}$.

\section{Conclusion}

In this paper, we have developed a two-warehouse inventory model for deteriorating items with noninstantaneous deterioration rates. The storage capacity of the owned warehouse is limited, whereas there is infinite storage space in the rented warehouse. Demand rate is a linear function of stock level with partially backlogged shortages and the backlogging rate is inverse function of time under the effect of inflation. The optimal values of total cost, total cycle length, and order quantity are calculated and sensitivity analysis is performed. Our model can be used in the cases of fruits, vegetables, cosmetic products, etc. This model can be extended by incorporating other parameters of inventory system.

\section{References}

1. Hartley, R.V., Operations Research- A Managerial Emphasis, California: Good Year Publishing Company, (1976).

2. Sarma, K.V.S. "A deterministic order level inventory model for deteriorating items with two storage facilities", European Journal of Operational Research, 29, pp. 70-73 (1987).

3. Kumari, R., Singh, S.R. and Kumar, N. "Two- 
warehouse inventory model for deteriorating items with partial backlogging under the conditions of permissible delay in payments", Int. Trans. Math. Sci. Comput, 1(1), pp. 123-134 (2008).

4. Agrawal, S. and Banerjee, S. "Two-warehouse inventory model with ramp-type demand and partially backlogged shortages", International Journal of System Science, 1, pp. 1-12 (2010).

5. Kumar, N., Singh, S.R. and Kumari, R. "Twowarehouse inventory model of deteriorating items with three-component demand rate and time proportional backlogging rate in fuzzy environment", International Journal of Industrial Engineering Computations, 4, pp. 587-598 (2013).

6. Singh, S.R., Rathore, H. and Saxena, N. "A two warehouse inventory model for deteriorating items with shortages under inflationary environment", 3rd International Conference on Recent Trends in Engineering \& Technology, Nasik, India, pp. 385-391 (2014).

7. Singh, S.R. and Rathore, H. "A two warehouse inventory model for deteriorating items with noninstantaneous deterioration and partial backlogging", Contemporary Computing (IC3), 2014 Seventh International Conference on, Noida, India, pp. 431-436 (2014).

8. Singh, S.R. and Rathore, H. "Two-warehouse reverse logistic inventory model for deteriorating item under learning effect", 4th International Conference on Soft Computing for Problem Solving, Springer, 2014 Silcher, India, pp. 45-57 (2014).

9. Sarkar, B., Mandal, B. and Sarkar, S. "Quality improvement and backorder price discount undercontrollable lead time in an inventory model", Journal of Manufacturing Systems, 35, pp. 26-36 (2015).

10. Sarkar, B. and Moon, I. "Improved quality, setup cost reduction, and variable backorder costs in an imperfect production process", International Journal of Production Economic, 155, pp. 204-213 (2014).

11. Khanra, S., Mandal, B. and Sarkar, B. "An inventory model with time dependent demand and shortages under trade credit policy", Economic Modelling, 35, pp. 349-355 (2013).

12. Sarkar, B., Barron, L.E.C., Sarkar, M. and Siggih, M.L. "An economic production quan-tity model with random defective rate, rework process and backorders for a single stage production system", Journal of Manufacturing Systems, 33(3), pp. 423-435 (2014).

13. Zhou, Y.-W. and Yang, S.-L. "A two-warehouse inventory model for items with stock-level-dependent demand rate", Int. J. Production Economics, 95, pp. 215-228 (2005).

14. Yadav, D., Singh, S.R. and Kumari, R. "Inventory model of deteriorating items with two-warehouse and stock dependent demand using genetic algorithm in fuzzy environment", The Yugoslav Journal of Operations Research, 22(1) (2012).
15. Singh, S.R., Kumari, R. and Kumar, N. "A deterministic two warehouse inventory model for deteriorating items with stock-dependent demand and shortages under the conditions of permissible delay", International Journal of Mathematical Modelling and Numerical Opti-misation, 2 (2011).

16. Gayen, M. and Pal, A.K. "A two- warehouse inventory model for deteriorating items with stock dependent demand rate and holding cost", Operational Research, 9, pp. 153-165 (2009).

17. Dye, C.Y. and Ouyang, L.Y. "An EOQ model for perishable items under stock dependent selling rate and time-dependent partial backlogging", European Journal of Operational Research, 163, pp. 776-783 (2005).

18. Ghiami, Y., Williams, T. and Wu, Y. "A two-echelon inventory model for a deteriorating item with stockdependent demand, partial backlogging and capacity constraints", European Journal of Operational Research, 231(3), pp. 587-597 (2013).

19. Sarkar, B. and Sarkar, S., "An improved inventory model with partial backlogging, time varying deterioration and stock-dependent demand", Economic Modelling, 30, pp. 924-932 (2013).

20. Sarkar, B., Saren, S. and Barrón, L.E.C. "An inventory model with trade-credit policy and variable deterioration for fixed lifetime products", Annals of Operations Research, 229(1), pp. 677-702 (2015).

21. Sarkar, M. and Sarkar, B. "An economic manufacturing quantity model with probabilistic deterioration in a production system", Economic Modelling, 31, pp. 245-252 (2013).

22. Hsu, P.H., Wee, H.M. and Teng, H.M. "Preservation technology investment for deterio-rating inventory", International Journal of Production Economics, 124(2), pp. 388-394 (2010).

23. Lee, Y.P. and Dye, C.Y. "An inventory model for deteriorating items under stock-dependent demand and controllable deterioration rate", Computers and Industrial Engineering, 63(2), pp. 474-482 (2012).

24. Hsieh, T.P. and Dye, C.Y. "A production-inventory model incorporating the effect of preservation technology investment when demand is fluctuating with time", Journal of Computational and Applied Mathematics, 239, pp. 25-36 (2013).

25. Dye, C.Y. "The effect of preservation technology investment on a non-instantaneous deteriorating inventory model", Omega, 41(5), pp. 872-880 (2013).

26. Xue, M.S., Zhang, J.X. and Tang, W.S. "Optimal temperature control for quality of perishable foods", ISA Transactions, 53(2), pp. 542-546 (2014).

27. Zhang, J.X., Bai, Z.Y. and Tang, W.S. "Optimal pricing policy for deteriorating items with preservation technology investment", Journal of Industrial and Management Optimization, 10(4), pp. 1261-1277 (2014). 
28. Tayal, S., Singh, S.R., Sharma, R. and Chauhan, A. "Two echelon supply chain model for deteriorating items with effective investment in preservation technology", International Journal of Mathematics in Operational Research, 6(1), pp. 84-105 (2014).

29. Zhang, J., Liu, G., Zhang, Q. and Bai, Z. "Coordinating a supply chain for deteriorating items with a revenue sharing and cooperative investment contract", Omega, The International Journal of Management Science, OMEGA-D-14-00325, pp. 1-27 (2014).

30. Buzacott, J.A. "Economic order quantity with inflation", Operational Research Quarterly, 26(3), pp. 553558 (1975).

31. Wee, H.M., Yu, J.C.P. and Law, S.T. "Two-warehouse inventory model with partial backordering and weibull distribution deterioration under inflation", Journal of Chinese Institute of Industrial Engineers, 22(6), pp. 451-462 (2005).

32. Yang, H.L. "Two-warehouse partial backlogging inventory model for deteriorating items under inflation", International Journal of Production Economics, 103, pp. 362- 370 (2006).

33. Singh, S.R. and Rathore, H. "Optimal payment policy for deteriorating item with preser-vation technology investment under trade credit and inflation", Recent Advances and Innovations in Engineering (ICRAIE), 2014 first International Conference on, Jaipur, India, pp. 1-6 (2014).

34. Singh, S.R. and Rathore, H. "A two-echelon inventory model with preservation technology investment in an inflationary environment", 1st International Science and Technology Congress 2014, Calcutta, India, pp. 480-488 (2014).

35. Singh, S.R. and Rathore, H. "Optimal payment policy with preservation technology investment and shortages under trade credit", Indian Journal of Science and Technology, 8(S7), pp. 203-212 (2015).

36. Singh, S.R., Kumari, R. and Kumar, N. "Replenishment policy for non-instantaneous deteriorating items with stock-dependent demand and partial back logging with two-storage facility under inflation", International Journal of Operations Research and Optimization, 1(1), pp. 161-179 (2010).

37. Singh, S.R., Kumar, N. and Kumari, R. "An inventory model for deteriorating items with shortages and stock-dependent demand under inflation for two-shops under one management", Opsearch, 47(4), pp. 311-329 (2010).
38. Patra, S.K. and Ratha, P.C. "An Inventory replenishment Policy for deteriorating Items under inflation in a stock dependent consumption market with shortages", International Journal of Transdisciplinary Research, 6(1), pp. 1-23 (2012).

39. Sarkar, B., Sana, S.S. and Chaudhuri, K. "A finite replenishment model with increasing demand under inflation", International Journal of Mathematics in Operational Research, 2(3), pp. 347-385 (2010).

40. Sarkar, B., Sana, S.S. and Chaudhuri, K. "An imperfect production process for time varying demand with inflation and time value of money - An EMQ model", Expert Systems with Applications, 38, pp. 13543-13548 (2011).

41. Sarkar, B., Mandal, P. and Sarkar, S. "An EMQ model with price and time dependent demand under the effect of reliability and inflation", Applied Mathematics and Computation, 231(15), pp. 414-421 (2014).

42. Singh, S.R. and Rathore, H. "An inventory model for deteriorating item with reliability consideration and trade credit", Pakistan Journal of Statistics and Operation Research, 10(3), pp. 349-360 (2014).

43. Singh, S.R. and Rathore, H. "Reverse logistic model for deteriorating items with non-instantaneous deterioration and learning effect", Information Systems Design and Intelligent Applications -Advances in Intelligent Systems and Computing, 339, pp 435-445 (2015).

\section{Biographies}

Shivraj Singh is Associate Professor of Mathematics at Choudhary Charan Singh University, Meerut (India). His research interests are in the areas of inventory control, inventory management, supply chain management, production, optimization, etc. He has published more than 151 research papers and is reviewer of many international journals. Professor Singh's research papers have been cited in many articles and textbooks.

Himanshu Rathore is pursuing $\mathrm{PhD}$ at Banasthali University, Rajasthan, India. She received her BSc and MSc degrees from the same university in 2005 and 2007, respectively. Her research interests are mainly in the area of inventory control model for deteriorating items in different environmental aspects. 